\title{
REKONSTRUKSI MEDIA PEMBELAJARAN VIDEO SCRIBE LISTRIK DINAMIS UNTUK SISWA KELAS XII SMA/MA
}

Risma Zunafaroh ${ }^{1}$, Ino Angga Putra ${ }^{2}$, dan Suci Prihatiningtyas ${ }^{3}$ ${ }_{1,2,3}$ Universitas KH. A. Wahab Hasbullah, Jombang, Indonesia Coresponding Author Email: inoanggaputra@unwaha.ac.id

\section{Info Artikel}

Diterima:

01 Oktober 2020

Disetujui:

03 Desember 2020

Dipublikasikan:

15 Desember 2020

\begin{abstract}
Abstrak:
Penelitian ini bertujuan untuk mengetahui kelayakan media pembelajaran, penguasaan konsep dan literasi sains siswa. Desain penelitian menggunakan desain pengembangan ADDIE. Kelayakan media dilihat berdasarkan hasil validasi ahli media dan ahli materi. Hasil penelitian menunjukkan bahwa media pembelajran video scribe lisrik dinamis yang telah dikembangkan memiliki karakteristik: 1) uji validasi produk diperoleh dari hasil nilai ahli media dan ahli materi sebesar 3,67 dengan klasifikasi layak. 2) uji keterbacaan diperoleh dari hasil angket respon guru dan respon siswa sebesar 3,58 dengan klasifikasi layak. Berdasarkan data di atas maka dapat disimpulkan bahwa media pembelajaran video scribe layak digunakan sebagai media pembelajaran fisika.
\end{abstract}

Kata kunci: Media pembelajaran, video scribe, listrik dinamis

\begin{abstract}
:
This study aims to determine the feasibility of learning media, students' mastery of concepts and scientific literacy. The research design uses the ADDIE development design. The feasibility of the media is seen based on the validation results of media experts and material experts. The results showed that the dynamic electric scribe video learning media that had been developed had the following characteristics: 1) the product validation test was obtained from the results of the media expert and material expert score of 3.67 with a proper classification. 2) the readability test was obtained from the results of the teacher response questionnaire and student responses of 3.58 with a proper classification. Based on the data above, it can be concluded that the Scribe video learning medla is suitable for use as a physics learning medium.

Keywords: Learning media, video scribe, dynamic electricity
\end{abstract}

Copyright $\odot 2020$ Edufisika: Jurnal Pendidikan Fisika 


\section{Pendahuluan}

Pendidikan memiliki peran penting dalam meningkatkan kualitas sumber daya manusia. Salah satu upaya yang dilakukan dalam meningkatkan kualitas pendidikan yaitu melaksanakan kurikulum yang berlaku secara maksimal. Permendikbud nomor 36 tahun 2018 menjelaskan bahwa pelaksanaan kurikulum 2013 menekankan pada pengembangan keseimbangan antara sikap spiritual, sosial, pengetahuan, dan keterampilan siswa dalam menerapkannya diberbagai situasi baik di sekolah maupun dimasyarakat. Kurikulum 2013 menuntut guru untuk terampil dalam mengelola pembelajaran dan siswa untuk aktif di dalam kegiatan pembelajaran (Putra \& Prihatinigtyas, 2018:607). Selain itu, Kurikulum 2013 menekankan beberapa prinsip kepada siswa yaitu aktif, kreatif, dan berpikir kritis dalam proses pembelajaran. Oleh karena itu, kurikulum 2013 perlu dilaksanakan secara optimal dengan guru sebagai motivator dan fasilitator dalam proses pembelajaran sehingga proses pembelajaran bisa terlaksana sesuai harapan.

Berdasarkan hasil observasi pada Madrasah Aliyah (MA) di Jombang, bahwa belum semuanya dapat menerapkan kurikulum 2013 secara maksimal. Hal tersebut disebabkan oleh beberapa hal diantaranya yaitu sarana prasarana yang belum memadahi, kegiatan pembelajaran yang yang hanya fokus pada guru menjelaskan dan siswa mendengarkan, kurangnya media pembelajaran, dan kurangnya minat membaca siswa. Selain itu pemilihan kegiatan pembelajaran yang kurang tepat dalam pembelajaran fisika dan rendahnya motivasi belajar siswa menjadi salah satu faktor yang mempengaruhi rendahnya penguasaan konsep dan literasi sains siswa. Selain itu, mata pelajaran fisika merupakan salah satu mata pelajaran yang kurang diminati oleh siswa.

Faktor yang menyebabkan siswa tidak menyukai pelajaran fisika adalah pandangan siswa yang menganggap fisika hanya berupa kumpulan teori dan rumus yang harus dihafalkan (Hanna dkk, 2016:24). Isyowati (2017:237) menambahkan bahwa materi fisika yang bersifat abstrak inilah yang membuat siswa harus dapat memahami konsep daripada hanya sekedar menghafalkan rumus. Pembelajaran fisika hanya berisi permasalahan konsep matematis dan penyelesaian soal-soal dengan rumus-rumus yang rumit (Rahmawati dkk, 2016).

Salah satu upaya yang dapat dilakukan dalam menumbuhkan penguasaan konsep siswa yaitu menggunakan media pembelajaran yang tepat. Media pembelajaran yang dianggap tepat adalah media pembelajaran berbasis teknologi, salah satunya yaitu menggunakan media pembelajaran video scribe. Video scribe ini juga dikenal dengan media sparkol (Pratiwi dkk, 2019;305) yaitu aplikasi lunak berbentuk video yang bisa digabungkan dengan peta konsep, gambar, suara, dan musik yang bisa menarik dan meningkatkan minat siswa untuk mengamati pelajaran secara efektif. Video scribe mampu menghadirkan perpaduan gambar, suara, dan desain yang menarik dalam proses pembelajaran agar dapat menarik perhatian dan minat siswa (Nulhakim, dkk., 2019:1). Wulandari (2016:119) menambahkan bahwa media pembelajaran video scribe mampu meningkatkan antusiasme siswa untuk memperhatikan proses pembelajaran.

Adapun dampak pengunaan video scribe dalam pembelajaran yaitu video scribe ini cukup efektif digunakan dalam proses pembelajaran di kelas (Jannah, 2019:71). Media pembelajaran video scribe ini juga memiliki nilai praktis digunakan dalam pembelajaran baik di sekolah maupun di rumah (Yudha dkk, 2016:106). Rahmawati, dkk (2016:1046) juga menyatakan bahwa media pembelajaran video scribe juga layak digunakan untuk meningkatkan hasil belajar siswa. Selain itu, Nulhakim, dkk. (2019:1) menambahkan bahwa melalui penggunaan video scribe dapat meningkatkan kemampuan literasi sains siswa dengan skor $\mathrm{N}$-gain sebesar 0,74 dalam kategori tinggi.

Materi pelajaran yang akan digunakan dalam penelitian ini adalah listrik dinamis. Listrik dinamis merupakan salah satu materi pelajaran fisika pada kelas XII semester ganjil. Listrik dinamis merupakan materi yang mengajarkan tentang pergerakan listrik atau arus listrik, sehingga listrik dinamis sering disebut dengan listrik yang dapat bergerak. Pada materi listrik dinamis terdapat beberapa sub bab materi yaitu arus listrik dan pengukurannya, Hukum Ohm, rangkaian listrik searah, dan daya listrik.

Berdasarkan penjelasan di atas maka penulis akan melakukan penelitian yang berjudul "Rekonstruksi Media Pembelajaran Video Scribe Listrik Dinamis untuk Siswa Kelas XII". Penggunaan media pembelajaran video scribe ini diharapkan dapat dijadikan alternatif media pembelajaran fisika. Kajian penelitian ini meliputi: (1) desain media pembelajaran video scribe untuk 
pembelajaran fisika, (2) Bagaimana kelayakan media pembelajaran video scribe untuk pembelajaran fisika.

\section{Metode Penelitian}

Penelitian ini adalah penelitian dan pengembangan R\&D (Research and Development). Penelitian ini dilakukan di kelas XII MA Mambaul Ulum Jombang pada semester genap bulan Maret tahun ajaran 2019/2020. Populasi dalam penelitian ini adalah peserta didik kelas XII MIPA I MA Mambaul Ulum pada tahun ajaran 2019/2020, tang terdiri dari 14 siswa. Teknik pengambilan sampling dilakukan dengan cara purposive sampling.

Prosedur

Penelitian pengembangan ini mengguanakan medel pengembangan ADDIE (Analysis, Design, Development, Implementation, Evaluation). Namun pada penelitian ini hanya pada tahap analysis, design, development, dan implementation saja. Analysis (Analisis) adalah proses pengidentifikasi masalah. Pada proses analisis ini terlebih dahulu dilakukan pengumpulan data terkait dengan permasalahan kemudian diidentifikasi pemecahan masalahnya melalui analisis materi, analisis karakteristik siswa dan perumusan tujuan. Design (Desain) yaitu pembuatan rancangan media yang akan dikembangkan. Tahap desain meliputi pembuatan storyline secara tertulis, menyiapkan komponen pendukung dan membuat media pembelajaran. Development (Pengembangan) yaitu proses pengembangan media pembelajaran ini dilakukan dengan melaksanakan rencana yang telah dirancang pada tahap desain. Kemudian mengkonsultasikan kepada dosen pembimbing untuk melakukan tindak lanjut yang akan dilakukan. Selanjutnya pelaksanaan validasi terhadap media pembelajaran kepada kepada ahli materi dan ahli media untuk mengetahui tingkat kelayakannya. Implementation (Implementasi) yaitu tahap mengimplementasikan atau menerapkan media yang telah dikembangkan. Dalam penelitian ini media pembelajaran yang sudah dinyatakan layak akan diuji cobakan kepada guru dan siswa. untuk mengetahui respon guru dan respon siswa.

\section{Data, Intrumen, dan Teknik Pengumpulan Data}

Instrument penilaian dalam penelitian adalah instrument kelayakan meliputi instrument validasi, instrument respon guru, dan instrument respon siswa. Pengumpulan data penelitian dengan cara uji validasi kelayakan kemudian pengisan kuisioner oleh guru dan siswa.

Teknik Analisis Data

Analisis data penelitian hanya mengkaji data kelayakan produk dengan menggunakan skala likert (Tabel 1).

Tabel 1. Pedoman Penilaian Skala Likert (Arikunto, 2014)

\begin{tabular}{cc}
\hline Keterangan & Nilai \\
\hline Baik/Setuju & 4 \\
Cukup Baik/Cukup Setuju & 3 \\
Kurang Baik/Kurang Setuju & 2 \\
Tidak Baik/Tidak Setuju & 1 \\
\hline
\end{tabular}

Hasil data angket tersebut akan dihitung kelayakannya dengan menggunakan rumus berikut ini:

Keterangan:

$$
\bar{x}=\frac{\sum x}{n}
$$

$\bar{x}=$ Nilai rata-rata

$\sum x=1$ Jumlah skor

$n=$ Jumlah 
Dengan kriteria terlihat pada tabel 2 sebagai berikut:

Tabel 2. Skala Tingkat Pencapaian (Arikunto, 2014)

\begin{tabular}{cc}
\hline Rentan Skor & Tingkat Kelayakan \\
\hline $3,28-4,00$ & Layak \\
$2,52-3,27$ & Cukup Layak \\
$1,76-2,51$ & Kurang Layak \\
$0,00-1,75$ & Tidak Layak \\
\hline
\end{tabular}

\section{Hasil Penelitian dan Pembahasan}

Data hasil penelitian diperoleh berdasarkan tahapan pengembangan dengan desain ADDIE sebagai berikut.

1. Tahap analisis (Analysis)

Tahap analisis ini terdiri atas beberapa tahapan yaitu tahap analisi materi, tahap analisi karakteristik siswa, dan tahap merumuskan tujuan. Hasil analisis materi didapatkan kumpulan materi yang berasal dari buku pelajaran "Fisika Peminatan untuk SMA/MA kelas XII Semester 1", buku referensi yang berjudul "Fisika Dasar II"serta video pembelajaran tentang materi listrik dinamis.

Hasil analisis karakteristik siswa diperoleh bahwa siswa kelas XII berada pada tahap operasional formal (usia 11-dewasa). Hasil analisi tahap merumuskan tujaun dengan menggunakan hasil analisi materi dan karakteristik siswa berdasarkan tujuan kompetensi dasar menurut kurikulum 2013.

\section{Tahap Perancangan (Design)}

Tahap perancangan meliputi tahap perancangan (design), kegiatan perencanaan yang dilakukan yaitu pengembangan draf video berdasarkan storyline yang telah dibuat, menyiapkan komponen pendukung berupa materi, background, pemilihan warna, gambar, musik instrumental, dan software aplikasi video scribe dan aplikasi filmora. Penyusunan desain video yaitu pembukaan, judul materi, Kompetensi Dasar (KD), Kompetensi Inti (KI), indikator pembelajaran, pembahasan materi, latihan soal, penutup.

\section{Tahap Pengembangan (Development)}

Data hasil tahap pengembangan ini didapat dari hasil validasi ahli media dan hasil validasi ahli materi. Hasil angket tersebut digunakan untuk mengetahui kelayakan media pembelajaran yang telah dibuat. Pada angket yang diberikan kepada para ahli tidak hanya berisi penilaian saja, akan tetapi juga berisi komentar ataupun saran untuk memperbaiki media pembelajaran tersebut. Berikut hasil penilaian validasi ahli media (Tabel 3) dan ahli materi (Tabel 4).

Tabel 3.Hasil Rekapitulasi Data Validasi Ahli Media

\begin{tabular}{llcl}
\hline No & \multicolumn{1}{c}{ Aspek } & Total skor & Kategori \\
& & & \\
\hline 1 & Aspek Pewarnaan & 4 & Layak \\
\hline 2 & Pemakaian kata dan bahasa & 4 & Layak \\
& & & \\
\hline 3 & Tampilan pada layar & 3,65 & Layak \\
\cline { 1 - 2 } 4 & Penyajian & 3,33 & Layak \\
\hline 5 & Animation dan suara & 3,67 & Layak \\
\hline \multicolumn{2}{c}{ Jumlah } & 18,65 & Layak \\
\hline & Rata-rata & 3,74 & \\
\hline
\end{tabular}


Berdasarkan data yang diperoleh, aspek pewarnaan memiliki tingkat kelayakan layak dengan skor rata-rata 4,0. Pada aspek pemakaian kata dan bahasa juga memiliki tingkat kelayakan yang layak dengan skor rata-rata sebesar 4,0.

Aspek tampilan pada layar juga memilik tingkat kelayakan yang layak dengan sekor rata-rata 3,65. Aspek menyajian mendapat tingkat kelayakan layak dengan skor 3,3. Aspek animation dan suara memiliki tingkat kelayakan layak dengan skor 3,67. Hasil rekapitulasi data hasil validasi ahli media diperoleh hasil skor sebesar 3,73 dengan tingkat kelayakan yang layak.

Tabel 4. Hasil Rekapitulasi Data Validasi Ahli Materi

\begin{tabular}{ccc}
\hline Aspek & Sekor rata-rata & Kategori \\
\hline Kesesuaian Materi dengan KD, KI, dan Indikator & 3,2 & Layak \\
Aspek Bahasa & 4 & Layak \\
\hline Rata-rata & 3,6 & Layak \\
\hline
\end{tabular}

Hasil analisis data hasil validasi ahli materi diperoleh hasil rentan skor sebesar 3,6 dengan tingkat kelayakan yang layak. Berdasarkan analisis data pada pada Tabel 3 hasil validasi ahli materi diperoleh hasil aspek Kesesuaian Materi dengan KD, KI, dan Indikator memiliki tingkat kelayakan layak dengan skor rata-rata 3,2. Pada aspek bahasa juga memiliki tingkat kelayakan yang layak dengan skor rata-rata sebesar 4,0. Berdasarkan hasil tersebut maka dapat menunjukkan bahwa materi pada video scribe ini sudah layak unuk digunakan sebagai salah satu media pembelajara fisika di kelas XII dengan materi listrik dinamis.

\section{Tahap implementasi (Implementation)}

Berdasarkan hasil respon guru mendapatkan skor sebesar 3,4 dengan tingkat kelayakan yang layak. Sedangkan hasil analisis dari respon siswa didapatkan hasil rata-rata skor sebesar 3,76 dengan tingkat kelayakan yang layak. Berdasarkan hasil respon guru dan respon siswa dapat disimpulkan bahwa media video scribe memiliki tingkat kelayakan layak dengan skor 3,58.

Beberapa hal yang harus diperhatikan pada penelitian ini meliputi (1) jumlah sampel yang sedikit karena hanya digunakan pada satu kelas dengan jumlah 14 pesertadidik, (2) respon guru hanya kepada 1 guru, (3) implementasi media pembelajaran hanya pada 1 kelas sehingga tidak ada kelas pembanding. Hasil penelitian dalam pengembangan media pembelajaran video scribe memiliki beberarapa kelebihan yaitu: (1) Media pembelajaran video scribe dapat digunakan siswa dimanapun dan kapanpun, (2) Materi yang disampaikan mudah dipahami, (3) Warna, gambar dan animasi yang digunakan menarik, (4) Berisi KD, KI, dan Indikator, (5) Terdapat ventilasi pengetahuan yang berisi informasi mengenai listrik, (6) Terdapat tokoh-tokoh listik dinamis.

Media pembelajaran video scribe yang telah dikembangkan ini memiliki beberapa kelemahan yaitu (1) media pembelajaran video scribe yang ada kurang interaktif karena belum adanya timbal balik antara media dengan pengguna, (2) ukuran video yang terlalu besar, (3) tidak bisa menampilkan gerak elektron secara bolak balik.

\section{Simpulan}

Berdasarkan hasil penelitian dan hasil analisi data dapat didimpulkan bahwa 1) media pembelajaran video scribe dinyatakan layak dengan skor 3,67. Media pembelajaran ini diharapkan dapat diterapkan di kelas. Media pembelajaran video scribe ini memiliki beberarapa kelebihan yaitu: (1) Media pembelajaran video scribe dapat digunakan siswa dimanapun dan kapanpun, (2) Materi yang disampaikan mudah dipahami, (3) Warna, gambar dan animasi yang digunakan menarik, (4) Berisi KD, KI, dan Indikator, (5) Terdapat ventilasi pengetahuan yang berisi informasi mengenai listrik, (6) Terdapat tokoh-tokoh listik dinamis. Saran pada hasil penelitian diantara lain Pengembangan media pembelajaran video scribe disusun berdasarkan kurikulum yang berlaku, karakteristik peserta didik dan kebutuhan peserta didik dan lapanga dan proses implementasi menggunakan sampel dengan jumlah yang lebih banyak dan ada kelas pembanding. Media 
pembelajaran ini mendapatkan hasil respon guru sebesar 3,4 dengan tingkat kelayakan yang layak dan pada respon siswa mendapatkan skor 3,76 dengan kelayakan layak.

\section{Referensi}

Arikunto, S. (2014). Prosedur Penelitian, Edisi Revisi VI. Jakarta. Rineka Cipta.

Hanna, D., Sutarto., \& Alex, H. 2016. Model Pembelajaran Tema Konsep Disertai Media Gambar pada Pembelajaran Fisika di SMA. Jurnal Pendidikan Fisika. Vol. 5 No.1 pp. 23-29.

Isyowati, A., Sentot, K., \& Supryono, K, H. 2017. Analisi Pembelajaran dan Kesulitan Siswa SMA Kelas XI terhadap Penguasaan Konsep Fisika. Proseding Seminar Nasional III Tahun 2017 "Biologi, Pembelajaran, dan Lingkunga Hidup Perspektif Interdisipliner" hal. 237-243.

Jannah, M., Alex, H., \& Yushardi. 2019. Aplikasi Media Pembelajaran Fisika Berbasis Sparkol Videoscribe pada Pokok Bahasan Suhu dan Kalor terhadap Hasil Belajar Siswa SMK. Jurnal Pembelajaran Fisika. Vol. 8 No. 2 pp. 65-72.

Nulhakim, L., Irania, I., \& Asep., S. 2019. The influence of using Sparkol videoscribe's learning media to increase science literacy on pressure concept. The 8th National Physics Seminar 2019 AIP Conf. Proc. 2169, 020003-1-020003-4.

Kemdikbud. 2018. Peraturan Menteri Pendidikan Dan Kebudayaan (Permendikbud) Republik Indonesia Nomor 36 Tahun 2018 Tentang Perubahan Atas Peraturan Menteri Pendidikan Dan Kebudayaan Nomor 59 Tahun 2014 Tentang Kurikulum 2013 Sekolah Menengah Atas/Madrasah Aliyah. Jakarta

Pratiwi, D, E., Sri, L., Mukarramah, M. 2019. Pengembangan Media Pembelajaran Fisika Menggunakan Sparkol Videoscribe. Indonesia Jurnal of Science and Mathematics Education. 02 (3): 303-309.

Putra, I.A., \& Prihatiningtyas, S. 2018. Implementasi Pembelajaran K13 oleh Mahasiswa pada Kegiatan Microteaching. Prosiding Seminar Nasional Sains dan Teknologi (SENASTEK) yang diselenggarakan oleh Fakultas Sains dan Teknologi Universitas Kanjuruhan Malang tanggal 21 Juli 2018. Malang: Universitas Kanjuruhan Malang.

Rahmawati, F., Soegimin., \& Soeparman, K. 2016. Pengembangan Perangkat Pembelajaran Fisika Model Inkuiri Terbimbing Berbantuan Videoscribe pada Materi Kalor Untuk Meningkatkan Hasil Belajar Siswa SMAN 1 Kedungwaru. Pendidikan Sains Pascasarjana Universitas Negri Surabaya. Vol. 5, No. 2

Wulandari, D. A. 2016. Pengembangan Media Pembelajaran Menggunakan Sparkol Videoscribe dalam Meningkatkan Minat Belajar Siswa pada Mata Pelajaran IPA Materi Cahaya Kelas VII di SMP Negri 01 Kejora Tahun Ajaran 2015/2016. In Skrips

Yudha, A, F, S., Asrul. \& Zulhendri, K. 2016. Pembuatan Bahan Ajar Berbasis Video Menggunakan Sparkol Videoscribe untuk Mepmbelajran Fisika Siswa Kelas X SMA. Pilar Of Phiysic Educatio. Vol.8 pp: 153-160. 